7. Reprod. Fert. (1971) 27, 91-99

\title{
SPERM PRODUCTION OF BOARS AS MEASURED FROM EPIDIDYMAL SPERM RESERVES AND QUANTITATIVE TESTICULAR HISTOLOGY
}

\author{
E. E. SWIERSTRA \\ Research Station, Canada Department of Agriculture, \\ Brandon, Manitoba, Canada
}

(Received 6th November 1970, revised 15th Fanuary 1971)

\begin{abstract}
Summary. Four methods of measuring daily sperm production (DSP) were evaluated using seventy-two boars. The DSP was determined; I, by unilaterally castrating boars 0 and $48 \mathrm{hr}$ after depletion of the epididymal sperm reserves and then measuring changes in the reserves (fourteen boars); II, by measuring changes in the epididymal sperm reserves of four groups of boars killed 5, 24, 52 and $72 \mathrm{hr}$ following depletion of the reserves (forty-six boars); III, by dividing the total number of spermatozoa in the right and left epididymis of sexually active boars by the epididymal transit time (twelve boars); IV, by quantitative testicular histology (same twelve boars as for Method III). Method I was unsuitable for estimating the DSP of individual boars because of normal variation in sperm numbers between epididymides within boars. Method II revealed that there was too much variation in epididymal sperm reserves among boars to obtain a reliable mean estimate of DSP for the forty-six boars. Method III did not give reliable results for individual boars because epididymal transit time varies among boars. It was concluded that the DSP of individual boars could best be measured by Method IV though Methods III and IV gave similar estimates for the mean DSP of the twelve boars $\left(15.0 \times 10^{9}\right.$ versus $\left.16.2 \times 10^{9}\right)$. The sperm output of these boars averaged $15.5 \times 10^{9} /$ day when ejaculates were collected at 72-hr intervals, suggesting little or no absorption of spermatozoa from the epididymides or excretion of spermatozoa in the urine of sexually active boars. The mean DSP/g of net testis was $24.5 \times 10^{6}$ (S.E. $\pm 0 \cdot 3$ ) as determined by quantitative histology. Only spermatozoa from the cauda epididymidis were ejaculated during depletion.
\end{abstract}

\section{INTRODUCTION}

Quantitative testicular histology has been used to determine daily sperm production (DSP) in the boar (Kennelly \& Foote, 1964; Swierstra, 1968a) and the bull (Amann \& Almquist, 1962b; Swierstra, 1966). In the bull, DSP has also been determined by counting the number of spermatids in suspensions of homogenized testes and dividing the total number counted by their lifespan (Amann \& Almquist, 1962b). Singh (1962) determined the DSP of 
boars by dividing the total epididymal sperm reserves by the time interval in days required for spermatozoa to pass through the epididymis. Recently, the DSP of the ram and bull has been measured by collecting spermatozoa and fluid directly from the rete testis of the living animal (Voglmayr, Waites \& Setchell, 1966; Voglmayr, Larsen \& White, 1970). Procedures for measuring DSP have been reviewed by Foote (1969) and Amann (1970).

The objectives of this research were (1) to evaluate three methods for measuring DSP from epididymal sperm reserves, (2) to compare DSP as measured from epididymal sperm reserves with DSP as measured by quantitative testicular histology, and (3) to compare sperm production with sperm output when semen samples were collected at 48- and 72-hr intervals.

\section{MATERIALS AND METHODS}

Three experiments were conducted to measure DSP from epididymal sperm reserves in the boar. All boars were kept in individual pens in a windowless piggery with a mean temperature of $17^{\circ} \mathrm{C} \pm$ only a few degrees and with light supplied from 08.00 to 17.00 hours. The boars had free access to water and were hand-fed $1.36 \mathrm{~kg}$ of pelleted ration ( $16 \%$ protein) twice daily. Using a dummy sow as teaser, semen was collected by artificial vagina (Swierstra \& Rahnefeld, 1967), and the sperm concentration was determined in the gel-free fraction of the ejaculate by optical density (Young, Foote, Turkheimer \& Hafs, 1960). The total number of spermatozoa per ejaculate was calculated, taking into account sperm losses in the collection equipment and gelatinous fraction of the ejaculate. Swierstra \& Rahnefeld (1967) determined that these losses equalled $3.28 \%$ of the number of spermatozoa present in the collection bottle.

\section{Epididymal sperm reserves}

Each epididymis was divided into the caput, corpus and cauda, and each part was processed separately. The tissue was minced with a pair of scissors and transferred to a Waring blender using $150 \mathrm{ml}$ of homogenizing solution. This solution consisted of physiological saline with $0.05 \%$ Triton X-100 added (Amann \& Lambiase, 1969). The suspension was homogenized for $1 \mathrm{~min}$ and transferred to a glass jar. The homogenates were diluted further with homogenizing solution to obtain sperm concentrations that were convenient for accurate haemocytometer counting ( 400 to 600 spermatozoa per chamber). Sperm concentrations were determined by counting spermatozoa present in ten large squares of each of eight haemocytometer chambers. Each chamber was filled with a different pipette and the homogenates were mixed for 2 min with a magnetic stirrer just before filling the pipettes.

\section{Daily sperm production by the testes}

The daily sperm production was determined from quantitative testicular histology (DSP-T) using a modification by Swierstra (1968a) of a method developed by Kennelly \& Foote (1964):

DSP-T per testis $=\frac{\text { Corrected testis volume } \times \text { Volume } \% \text { round spermatid nuclei in the testis }}{\text { Av. volume/round spermatid nucleus } \times \text { Life-span of round spermatids in days }}$ 
The corrected testis volume was obtained by the following formula:

Corrected testis volume $=$

$$
\left[\left(\begin{array}{c}
\text { Gross testis weight }- \\
\text { Tunica albuginea weight }
\end{array}\right)-\text { Volume of mediastinum testis }\right] \times \text { Shrinkage correction }
$$

Tissue samples were taken from three locations in the testes: near the caput epididymidis, midway between the poles of the testis and near the cauda epididymidis. The samples were fixed in Allen's fixative (Gray, 1964) for 3 days and processed routinely for embedding in paraffin wax. The tissue was serially sectioned $(8 \mu \mathrm{m})$ and stained with a Feulgen technique using fast green as a counterstain. The percentage volume of round spermatid nuclei in the testes was determined by the method of Chalkley (1943).

\section{Experiment 1}

Ejaculates were collected at 48-hr intervals from seven Yorkshire and seven Lacombe boars for 8 weeks. The last semen collection on this schedule was made in the morning. Epididymal sperm reserves were further depleted by collecting a second semen sample from each boar on the afternoon of the same day and another the following morning. One randomly selected testis of each boar was removed after the last semen collection and the other $48 \mathrm{hr}$ later. At castration, the Yorkshire boars were 316 days (S.E. \pm 4 ) old and weighed $140 \mathrm{~kg}$ (S.E. \pm 5 ). Corresponding figures for the Lacombe boars were 332 days (S.E. \pm 5 ) and $157 \mathrm{~kg}$ (S.E. \pm 4 ). Daily sperm production (DSP-E ${ }_{1}$ ) was determined from the epididymal sperm reserves by subtracting the sperm reserves present at $0 \mathrm{hr}$ from the sperm reserves present at $48 \mathrm{hr}$. The value thus obtained can be taken directly as a measure of DSP-E $E_{1}$ per boar, because it represented repletion of the sperm reserves of only one testis over a 2-day period (Foote, Kennelly \& Swierstra, 1965). The DSP-T was determined by classifying 700 'random hits' (Chalkley, 1943) per location or 2100 hits per testis.

Sperm production was compared with the average sperm output in the last ten ejaculates collected on the regular $48 \mathrm{-hr}$ collection schedule taking into account sperm losses in the collection equipment and gelatinous fraction of the ejaculate. Detailed information on the semen characteristics of these boars have been presented elsewhere (Swierstra \& Rahnefeld, 1967).

\section{Experiment 2}

Twenty-four Yorkshire and twenty-two Lacombe boars were used in this experiment. Semen was collected from these boars every $72 \mathrm{hr}$ for 5,10 or 15 weeks, after which the epididymal sperm reserves were depleted as outlined under Exp. 1. The boars were assigned to four similar groups on the basis of body weight and mean number of spermatozoa in the last ten ejaculates collected on the regular 72-hr schedule. Group I consisted of seven Yorkshire and five Lacombe boars; Group II of seven Yorkshire and seven Lacombe boars; and Groups III and IV both included five boars from each breed. Groups I, II, III and IV were killed 5, 24, 52 and $72 \mathrm{hr}$ after depletion. At killing, the Yorkshire boars were 320 (S.E. \pm 3 ) days old and weighed $132 \mathrm{~kg}$ (S.E. \pm 2 ). The age and weight of the Lacombe boars were 321 days (S.E. \pm 2 ) and $147 \mathrm{~kg}$ 
(S.E. \pm 2$)$, respectively. The mean daily sperm production (DSP-E 2 ) was determined from the repletion rate of the epididymal sperm reserves.

The DSP-T was measured for Group II by classifying 1400 'random hits' per location or 4200 hits per testis. Sperm production was compared with the average sperm output in the last ten ejaculates collected on the regular 72-hr collection schedule.

\section{Experiment 3}

Ejaculates were collected at 72-hr intervals from six Yorkshire and six Lacombe boars for an 11-week period, and killed $24 \mathrm{hr}$ after the last semen collection. At slaughter, the Yorkshire boars were 334 days (S.E. \pm 6 ) old and weighed $166 \mathrm{~kg}$ (S.E. \pm 3 ). Corresponding figures for the Lacombe boars were 337 days (S.E. \pm 3 ) and $178 \mathrm{~kg}$ (S.E. \pm 2 ).

Daily sperm production $\left(\mathrm{DSP}_{3} \mathrm{E}_{3}\right.$ ) was determined from the epididymal sperm reserves by dividing the total sperm reserves in the right and left epididymides by the number of days required for spermatozoa to pass through the epididymis. Studies with tritiated thymidine, in which semen was collected from eight boars at 24-hr intervals, have indicated a mean minimum transit time through the epididymis of $10 \cdot 2$ days (S.E. \pm 0.5 ). The percentage of labelled spermatozoa increased from $18 \%$ on the 1 st day to $58 \%$ on the 2 nd day after labelled spermatozoa appeared in the ejaculate (Swierstra, 1968b, unpublished data). In this study, therefore, 10.7 days were taken as the average

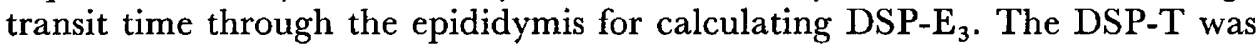
determined by classifying 1400 'random hits' per location or 4200 hits per testis. Sperm production was compared with the average sperm output in the last ten ejaculates after allowing for sperm losses as before.

\section{RESULTS}

\section{Experiment 1}

The mean DSO of the fourteen boars was $13 \cdot 1 \times 10^{9}$ (Table 1 ), and there was no significant difference between breeds with respect to sperm output. The mean estimate for daily sperm production was $16.6 \times 10^{9}$ when based on quantitative testicular histology and $11.5 \times 10^{9}$ when based on sperm repletion rate in the epididymides (DSP-E $\mathrm{E}_{1}$ ). The DSP-E $\mathrm{E}_{1}$ estimates for individual boars ranged from $+40.9 \times 10^{9}$ to $-10.1 \times 10^{9}$ with a coefficient of variation of $142 \%$. Sperm output was correlated with DSP-T $(r=0.61, P<0.05)$ and with testis weight ( $\mathrm{r}=0.57, P<0.05)$. Correlations between DSO and DSP-E ${ }_{1}(\mathrm{r}=0.19)$ and between DSP-T and DSP-E D $_{1}(r=0.02)$ were not significant.

The epididymal sperm reserves in the caput and corpus were similar for the depleted and repleted epididymides, indicating that only spermatozoa from the cauda were ejaculated (Table 1 ).

\section{Experiment 2}

The mean epididymal sperm reserves per boar for Groups I, II, III and IV were $128.2,150.4,142.4$ and $165.8 \times 10^{9}$, respectively (Table 2 ). The linear regression equation including all data was $\mathrm{Y}=131 \cdot 37\left(10^{9}\right)+0 \cdot 42 \mathrm{X}\left(10^{9}\right)$, 
Table 1

EPIDIDYMAL SPERM RESERVES OF SEVEN YORKSHIRE AND SEVEN LACOMBE BOARS UNILATERALLY CASTRATED AT 0 AND 48 HR AFTER DEPLETION OF THE EPIDIDYMAL SPERM RESERVES* (EXP. 1)

\begin{tabular}{l|rc}
\hline \multirow{2}{*}{\multicolumn{1}{c|}{ Characteristic }} & \multicolumn{2}{|c}{ Time after depletion } \\
\cline { 2 - 3 } & $0 \mathrm{hr}$ & $\mathbf{4 8} \mathrm{hr}$ \\
\hline Testis weight (g) & $339 \pm 15$ & $349 \pm 15$ \\
Epididymal weight (g) & $99 \pm 4$ & $108 \pm 5$ \\
Epididymal sperm reserves $\left(10^{9}\right)$ & & \\
Caput & $25 \cdot 1 \pm 3 \cdot 2$ & $23 \cdot 2 \pm 3 \cdot 2$ \\
Corpus & $18 \cdot 5 \pm 2 \cdot 5$ & $18 \cdot 1 \pm 2 \cdot 0$ \\
Cauda & $30 \cdot 8 \pm 3 \cdot 3$ & $44 \cdot 6 \pm 3 \cdot 7$ \\
Per side & $74 \cdot 4 \pm 6 \cdot 0$ & $85 \cdot 9 \pm 6 \cdot 5$ \\
DSP-E ${ }_{1} \dagger\left(10^{9}\right)$ & & $11 \cdot 5 \pm 4 \cdot 3$ \\
DSP-T $\$\left(10^{9}\right)$ & & $16 \cdot 6 \pm 0 \cdot 8$ \\
DSOS $\left(10^{9}\right)$ & & $13 \cdot 1 \pm 0 \cdot 8$ \\
& & \\
\hline
\end{tabular}

* Values in the body of the table are means \pm S.E.

+ Daily sperm production obtained by subtracting the epididymal sperm reserves present after depletion from the epididymal sperm reserves after $\mathbf{4 8} \mathrm{hr}$ of repletion.

$\ddagger$ Daily sperm production calculated from quantitative testicular histology.

Mean number of spermatozoa in the last ten ejaculates collected at $48-\mathrm{hr}$ intervals divided by the collection interval in days.

TABLE 2

EPIDIDYMAL SPERM RESERVES OF TWENTY-FOUR YORKSHIRE AND TWENTY-TWO LACOMBE BOARS KILLED AT DIFFERENT INTERVALS AFTER DEPLETION OF THE EPIDIDYMAL SPERM RESERVES* (EXP. 2)

\begin{tabular}{|c|c|c|c|c|}
\hline \multirow[b]{2}{*}{ Characteristic } & \multicolumn{4}{|c|}{ Time after depletion } \\
\hline & $5 \mathrm{hr}$ & $24 \mathrm{hr}$ & $52 h r$ & $72 \mathrm{hr}$ \\
\hline $\begin{array}{c}\text { No. of boars } \\
\text { Yorkshire } \\
\text { Lacombe }\end{array}$ & $\begin{array}{l}7 \\
5\end{array}$ & $\begin{array}{l}7 \\
7\end{array}$ & $\begin{array}{l}5 \\
5\end{array}$ & $\begin{array}{l}5 \\
5\end{array}$ \\
\hline Testis weight (g) & $293 \pm 9$ & $313 \pm 9$ & $289 \pm 8$ & $310 \pm 11$ \\
\hline Epididymal weight (g) & $60 \pm 3$ & $66 \pm 2$ & $62 \pm 2$ & $66 \pm 3$ \\
\hline $\begin{array}{l}\text { Epididymal sperm reserves }\left(10^{9}\right) \\
\text { Caput } \\
\text { Corpus } \\
\text { Cauda } \\
\text { Per side } \\
\text { Per boar }\end{array}$ & $\begin{array}{rr}21.4 \pm 1.2 \\
15.2 \pm 1.8 \\
27.5 \pm 2.7 \\
64.1 \pm 4.5 \\
128.2 \pm 12.8\end{array}$ & $\begin{array}{rr}23 \cdot 7 \pm 1.5 \\
16 \cdot 2 \pm 1.4 \\
35 \cdot 3 \pm 2.9 \\
75 \cdot 2 \pm 4.7 \\
150.4 \pm 13.1\end{array}$ & $\begin{array}{rr}20 \cdot 6 \pm 1 \cdot 2 \\
16 \cdot 1 \pm & 1 \cdot 3 \\
34 \cdot 5 \pm & 3 \cdot 1 \\
71.2 \pm & 4 \cdot 4 \\
142 \cdot 4 \pm 11.9\end{array}$ & $\begin{array}{r}23.9 \pm 1.4 \\
16.4 \pm 1.5 \\
42.6 \pm 2.5 \\
82.9 \pm 4.3 \\
165.8 \pm 12 \cdot 0\end{array}$ \\
\hline DSO $+\left(10^{9}\right)$ & $10 \cdot 1 \pm 0.5$ & $10.9 \pm 0.8$ & $10 \cdot 6 \pm 0.5$ & $10 \cdot 9 \pm 0.7$ \\
\hline
\end{tabular}

* Values in the body of the table are means \pm S.E.

† Mean number of spermatozoa in the last ten ejaculates collected at $72-\mathrm{hr}$ intervals divided by the collection interval in days. 
where $\mathrm{Y}$ is the predicted epididymal sperm reserve for the right and left testes, and $\mathrm{X}$ is the time interval after depletion in hours (Text-fig. 1). The sample standard deviation of the regression coefficient $\left(\mathrm{S}_{\mathrm{b}}\right)$ was $0.25 \quad(P=0 \cdot 10)$. Groups I and II each contained two boars with large epididymal sperm reserves. By excluding the two values outside the $95 \%$ confidence limits from the calculation, the linear regression coefficient was significantly different from zero $\left(\mathrm{S}_{\mathrm{b}}=0 \cdot 22\right)$.

The DSP-T for Group II was $13.8 \times 10^{9}$ (S.E. $\pm 0 \cdot 6$ ), and the DSP-T/g of net testis weight (gross testis weight minus the weight of the tunica albuginea) was $23.5 \times 10^{6}$. Daily sperm production calculated from the repletion rate of

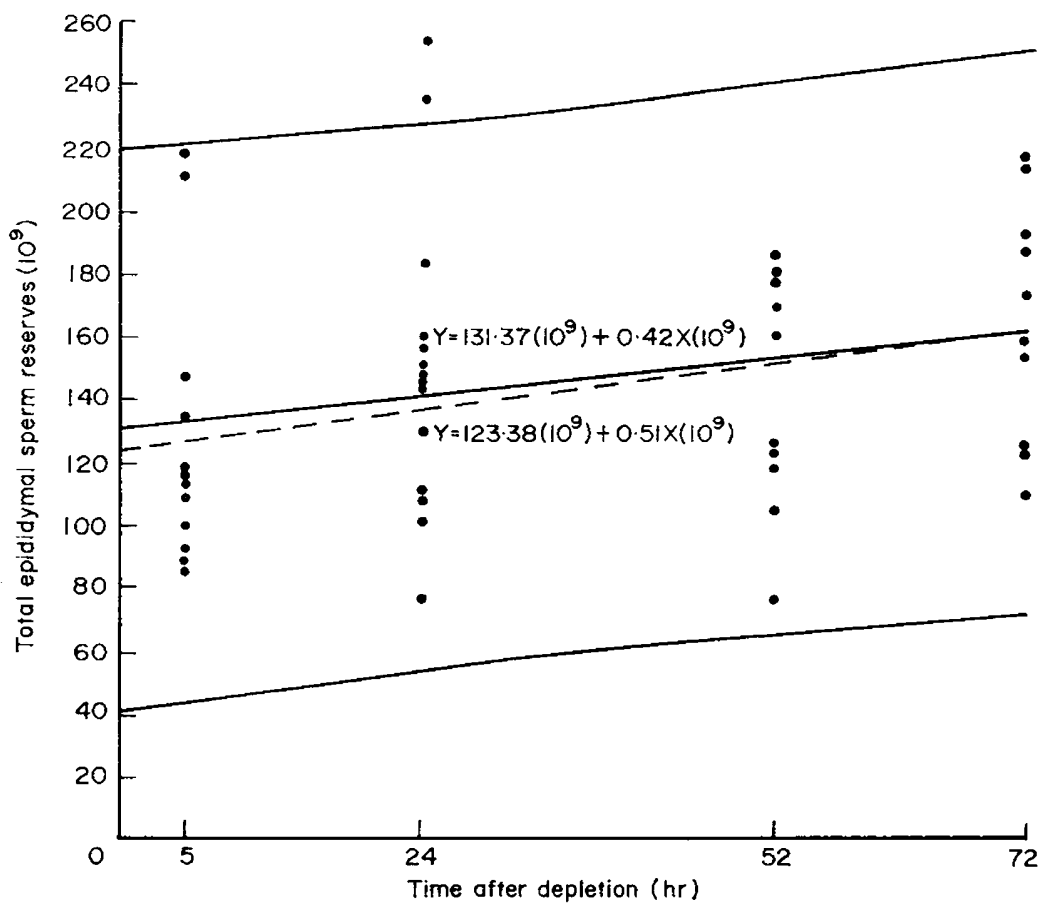

TEXT-FIG. 1. Epididymal sperm reserves of four groups of boars killed 5, 24, 52 and $72 \mathrm{hr}$ after depletion. Sample regression including all data $(-)$; sample regression excluding two boars outside the $95 \%$ confidence limits $(---)$.

the epididymal sperm reserves (DSP-E $\mathrm{E}_{2}$ ) was $10.08 \times 10^{9}$ when using the equation $\mathrm{Y}=131.37\left(10^{9}\right)+0.42 \mathrm{X}\left(10^{9}\right)$, and $12.24 \times 10^{9}$ when using the equation $\mathrm{Y}=123.38\left(10^{9}\right)+0.51 \mathrm{X}\left(10^{9}\right)$. These estimates are 73 and $89 \%$ of the value $13.8 \times 10^{9}$ for DSP-T. The DSO was $10.9 \times 10^{9}$ (S.E. \pm 0.8$)$ or $79 \%$ of the DSP-T.

\section{Experiment 3}

There was no significant difference between breeds with respect to sperm output and the DSP, as determined by quantitative histology, was similar for the two breeds (Table 3 ). The epididymal sperm reserves varied considerably among boars and between testes within boars (Table 4). The overall DSP-T, DSP-E 3 and DSO for the twelve boars were $16.3 \times 10^{9}$ (S.E. \pm 0.5 ), $15.0 \times 10^{9}$ (S.E. \pm 
TABLE 3

EPIDIDYMAL SPERM RESERVES OF SIX YORKSHIRE AND SIX LACOMBE BOARS HAVING BEEN ON A 72-HR SEMEN GOLLEGTION SCHEDULE AND KILLED 24 HR AFTER THE LAST SEMEN COLLECTION (EXP. 3)

\begin{tabular}{|c|c|c|}
\hline \multirow[b]{2}{*}{ Characteristic } & \multicolumn{2}{|c|}{ Mean $\pm S . E}$. \\
\hline & Yorkshire & Lacombe \\
\hline Testis weight $(\mathrm{g})$ & $357 \pm 6$ & $360 \pm 13$ \\
\hline Epididymal weight (g) & $69 \pm 3$ & $70 \pm 3$ \\
\hline $\begin{array}{l}\text { Epididymal sperm reserves }\left(10^{9}\right) \\
\text { Caput } \\
\text { Corpus } \\
\text { Cauda } \\
\text { Per side } \\
\text { Per boar }\end{array}$ & $\begin{array}{r}22 \cdot 3 \pm 2 \cdot 3 \\
19 \cdot 2 \pm 2 \cdot 4 \\
38 \cdot 7 \pm 3 \cdot 6 \\
80 \cdot 2 \pm 4 \cdot 8 \\
160 \cdot 4 \pm 13 \cdot 8\end{array}$ & $\begin{array}{r}34 \cdot 1 \pm 2 \cdot 5 \\
16 \cdot 0 \pm 1 \cdot 6 \\
30 \cdot 8 \pm 2 \cdot 5 \\
80 \cdot 9 \pm 5 \cdot 5 \\
161 \cdot 8 \pm 14 \cdot 0\end{array}$ \\
\hline $\begin{array}{l}\operatorname{DSP}_{-E_{3}}^{*}\left(10^{9}\right) \\
\text { DSP-T }\left(10^{9}\right) \\
\operatorname{DSO} \neq\left(10^{9}\right)\end{array}$ & $\begin{array}{l}15 \cdot 0 \pm 1 \cdot 3 \\
16 \cdot 5 \pm 0.5 \\
15 \cdot 3 \pm 0 \cdot 2\end{array}$ & $\begin{array}{l}15 \cdot 1 \pm 1.3 \\
16 \cdot 0 \pm 0.9 \\
15.8 \pm 0.8\end{array}$ \\
\hline
\end{tabular}

* Daily sperm production calculated from epididymal sperm reserves.

$\dagger$ Daily sperm production calculated from quantitative testicular histology.

$\ddagger$ Mean number of spermatozoa in the last ten ejaculates divided by the collection interval in days.

0.9 ) and $15.5 \times 10^{9}$ (S.E. \pm 0.4 ), respectively. The DSP-T/g of net testis weight was similar to that found in Exp. $2\left(24.2 \times 10^{6}\right.$ versus $\left.23.5 \times 10^{6}\right)$. Sperm output was significantly correlated with DSP-T $(r=0.65, P<0.05)$ and with paired testis weight $(\mathrm{r}=0.70, P<0.05)$. There was no significant correlation between DSP-T and DSP-E $3(r=0 \cdot 25)$. Sperm output equalled $95 \%$ of the DSP-T and $103 \%$ of the DSP-E ${ }_{3}$.

Considering all three experiments, the overall mean DSP-T/g of testis

TABLE 4

VARIATYON IN EPIDIDYMAL SPERM RESERVES BETWEEN RIGHT AND LEFT TESTES, AND AMONG BOARS HAVING BEEN ON A 72-HR SEMEN GOLLECTION SGHEDULE AND KILLED 24 HR AFTER THE LAST SEMEN COLLEGTION

\begin{tabular}{|c|c|c|c|c|c|}
\hline \multirow[b]{3}{*}{ Boar } & \multicolumn{2}{|c|}{ Corkshire boars } & \multicolumn{3}{|c|}{ Lacombe boars } \\
\hline & \multicolumn{2}{|c|}{ Sperm numbers $\left(10^{9}\right)$} & \multirow[b]{2}{*}{ Boar } & \multicolumn{2}{|c|}{ Sperm numbers $\left(10^{9}\right)$} \\
\hline & $\begin{array}{c}\text { Right } \\
\text { epididymis }\end{array}$ & $\begin{array}{c}\text { Left } \\
\text { epididymis }\end{array}$ & & $\begin{array}{c}\text { Right } \\
\text { epididymis }\end{array}$ & $\begin{array}{c}\text { Left } \\
\text { epididymis }\end{array}$ \\
\hline $\begin{array}{l}1 \\
2 \\
3 \\
4 \\
5 \\
6\end{array}$ & $\begin{array}{l}95 \cdot 5 \\
91 \cdot 3 \\
52 \cdot 1 \\
88 \cdot 1 \\
66 \cdot 3 \\
64 \cdot 7\end{array}$ & $\begin{array}{r}97.3 \\
104.2 \\
65.4 \\
94.5 \\
71.9 \\
71.6\end{array}$ & $\begin{array}{r}7 \\
8 \\
9 \\
10 \\
11 \\
12\end{array}$ & $\begin{array}{r}99 \cdot 3 \\
77 \cdot 8 \\
60 \cdot 3 \\
64 \cdot 2 \\
73 \cdot 0 \\
119 \cdot 0\end{array}$ & $\begin{array}{r}108.9 \\
73.2 \\
62.2 \\
67 \cdot 7 \\
88.5 \\
76.8\end{array}$ \\
\hline Mean & $76 \cdot 3$ & $84 \cdot 2$ & & $82 \cdot 3$ & $79 \cdot 6$ \\
\hline
\end{tabular}


was $24.2 \times 10^{6}$ (S.E. \pm 0.4 ) for the Yorkshire boars and $24.8 \times 10^{6}$ (S.E. \pm 0.4 ) for the Lacombe boars.

\section{DISCUSSION}

Evidence from Exps. 1 and 2 suggests that only sperm numbers in the cauda epididymidis of the boar are reduced by repeated ejaculation (Tables 1 and 2). This agrees with results obtained in bulls and rabbits (Amann \& Almquist, 1962a; Kirton, Desjardins \& Hafs, 1967). In Exp. 1, DSP estimated from replenishment of epididymal sperm reserves after unilateral castration was about $31 \%$ lower than using quantitative testicular histology (Table 1).

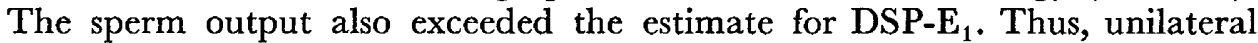
castration appears to alter epididymal function or interfere with the release of spermatozoa from the remaining testis. Furthermore, because of the variation in sperm reserves between epididymides within boars (Table 4), it is concluded that unilateral castration or any technique involving ligation of the epididymides (Foote et al., 1965) will not be likely to give reliable results for measuring DSP in individual boars.

In Exp. 2, it was postulated that the mean DSP of the forty-six boars could be determined from the rate of sperm accumulation in the epididymides following depletion. However, in each of Groups I and II (5 and $24 \mathrm{hr}$ after depletion) there were two boars with large epididymal sperm reserves (Text-fig. 1). In fact, three of these four boars had epididymal sperm reserves exceeding those of the boars in Group IV (72 hr after depletion). These four boars affected the slope of the regression line to a considerable extent. Because of this variation, forty-six boars were insufficient to provide an accurate mean value for DSP.

Sperm production and sperm output were of similar magnitude in Exp. 3 (Table 3) suggesting that, in sexually active boars, few if any spermatozoa are absorbed from the epididymis or excreted in the urine. This was further verified by collecting urine from two boars that had been on a regular semen collection schedule. For the first 3 days after the last semen collection, the urine of these boars was devoid of spermatozoa. In sexually inactive rams, it has been shown that there is little resorption of spermatozoa in the epididymis, vas deferens or ampulla. These rams eliminated $88 \%$ of the DSP in the urine. However, sperm output in the urine was 'severely depressed for several days' after ejaculates had been collected from the rams (Lino, Braden \& Turnbull, 1967).

As transit time of spermatozoa through the epididymis varies among boars, DSP for individual boars can be determined more accurately by quantitative testicular histology than by dividing the epididymal sperm reserves by the mean transit time. Swierstra (1968b, unpublished data) found that the minimum transit time through the epididymides of eight Yorkshire boars ranged from 9 to 13 days. This variation means that the DSP-E ${ }_{3}$ of some boars will be underestimated and of others overestimated by using a mean of 10.7 days and this probably accounts for the low correlation between DSP-E 3 and DSP-T. However, a mean DSP for a group of boars can be determined from the epididymal sperm reserves fairly accurately. Only sexually active animals should be 
considered, because sperm production and output have to be stabilized. In sexually inactive males, the epididymal sperm reserve increases considerably and this would result in erroneous values for DSP (Singh, 1962). It is postulated that reliable DSP estimates for individual animals can only be obtained by measuring epididymal transit time and epididymal sperm reserves in the same animals. Estimates for DSP so obtained should be comparable to those obtained by quantitative testicular histology.

\section{ACKNOWLEDGMENT}

The author gratefully acknowledges the technical assistance of $\mathrm{Mr} \mathrm{H}$. H. S. Bell and Mr W. D. Sutherland.

\section{REFERENCES}

Amann, R. P. (1970) Sperm production rates. In: The Testis, Vol. I, pp. 433-482. Eds. A. J. Johnson, W. R. Gomes and N. L. VanDemark. Academic Press, New York and London.

Amann, R. P. \& Almquist, J. O. (1962a) Reproductive capacity of dairy bulls. VI. Effect of unilateral vasectomy and ejaculation frequency on sperm reserves; aspects of epididymal physiology. 7. Reprod. Fert. 3, 260.

Amann, R. P. \& Almouist, J. O. (1962b) Reproductive capacity of dairy bulls. VIII. Direct and indirect measurement of testicular sperm production. F. Dairy Sci. 45, 774 .

Amann, R. P. \& Lambiase, J. T. (1969) The male rabbit. III. Determination of daily sperm production by means of testicular homogenates. 7. Anim. Sci. 28, 369.

Chalkley, H. W. (1943) Method for quantitative morphologic analysis of tissues. 7. natn. Cancer Inst. 4, 47.

Foote, R. H. (1969) Research techniques to study reproductive physiology in the male. In: Techniques and Procedures in Animal Science Research. American Society of Animal Science, c/o Q Corporation, Albany, New York.

Foote, R. H., Kennelly, J.J. \& Swierstra, E. E. (1965) Predicting maximum daily sperm production by the testis. Cornell Univ. Lab. Proc. 14, 1.

Gray, P. (1964) Handbook of basic microtechnique, 3rd edn, p. 91. McGraw-Hill, New York.

Kennelly, J. J. \& Foote, R. H. (1964) Sampling boar testes to study spermatogenesis quantitatively and to predict sperm production. 7. Anim. Sci. 23, 160.

Kirton, K. T., Desjardins, C. \& Hafs, H. D. (1967) Distribution of sperm in male rabbits after various ejaculation frequencies. Anat. Rec. 158, 287.

Lino, B. F., Braden, A. W. H. \& Turnbure, K. E. (1967) Fate of unejaculated spermatozoa. Nature, Lond. 213, 594.

Singh, G. (1962) Réserves spermatiques épididymaires chez le verrat. Annls Biol. anim. Biochim. Biophys. $2,47$.

SwIERstra, E. E. (1966) Structural composition of Shorthorn bull testes and daily spermatozoa production as determined by quantitative testicular histology. Can. 7. Anim. Sci. 46, 107.

Swierstra, E. E. (1968a) A comparison of spermatozoa production and spermatozoa output of Yorkshire and Lacombe boars. 7. Reprod. Fert. 17, 459.

Swierstra, E. E. (1968b) Cytology and duration of the cycle of the seminiferous epithelium of the boar; duration of spermatozoan transit through the epididymis. Anat. Rec. 161, 171.

SwIERstra, E. E. \& RAHNEFELD, G. W. (1967) Semen and testis characteristics in young Yorkshire and Lacombe boars. 7. Anim. Sci. 26, 149.

Voglmayr, J. K., Larsen, L. H. \& White, I. G. (1970) Metabolism of spermatozoa and composition of fluid collected from the rete testis of living bulls. $\mathcal{F}$. Reprod. Fert. $21,449$.

Voglmayr, J. K., Waites, G. M. H. \& Setchell, B. P. (1966) Studies on spermatozoa and fluid collected directly from the testis of the conscious ram. Nature, Lond. 210, 861.

Young, D. C., Foote, R. H., Turkhedmer, A. R. \& HaFs, H. D. (1960) A photoelectric method for estimating the concentration of sperm in boar semen. F. Anim. Sci. 19, 20. 